\title{
Educação Física escolar: cultura, currículo e conteúdo
}

\author{
Douglas Danilo Dittrich* \\ Juliane Sonda** \\ Florise Maria Fiorese*** \\ Ângelo Ricardo de Souza****
}

\begin{abstract}
RESUMO
Este trabalho é resultado de um conjunto de estudos desenvolvido pelos autores com o objetivo de entender melhor o fenômeno da Educação Física Escolar, mais particularmente no que se refere aos seus objetivos e conteúdos. O texto foi redigido com base nas análises dos resultados de um projeto de pesquisa desenvolvido por um dos autores, em uma escola da periferia de Curitiba. Após discussão teórica relacionando conhecimento, cultura e conteúdo escolar, o texto apresenta alternativas para o entendimento e encaminhamento pedagógico desta disciplina escolar.

Palavras-chave: Educação Física escolar, cultura escolar, conhecimento.
\end{abstract}

\begin{abstract}
This work results from developed studies to understand the Physical Education in Elementary School, present Physical Education objectives knowledge better. The empirical basis to this text came out of a research developed by one of the writers in a Public School in Curitiba surroundings. After a theoretical discussion about knowledge, culture and school

* Professor da Rede Municipal de Ensino de Curitiba. Especialista. ddittrich@uol.com.br

** Professora da Rede Municipal de Ensino de Curitiba e da Rede Estadual de Ensino do Paraná. Especialista. jsonda@uol.com.br

*** Professora da Rede Municipal de Ensino de Curitiba e da Rede Estadual de Ensino do Paraná. Especialista. florise@uol.com.br

***** Professor do Departamento de Planejamento e Administração Escolar, UFPR. Mestrando em Educação. angelo@educacao.ufpr.br
\end{abstract}


contents the text preents some alternatives for understanding a pedagogical methodology of this scholar discipline.

Key-words: Physical Education, school culture, knowledge.

\section{Introdução}

Este texto busca discutir alternativas de entendimento para os principais fenômenos presentes na Educação Física Escolar, no que tange à compreensão dos seus objetivos e conteúdos.

Na base empírica para este trabalho, descreve-se as atividades desenvolvidas em 1998, através do Projeto "EDUCAÇÃO FÍSICA: consolidação de uma nova proposta pedagógica"1 , junto às séries iniciais do Ensino Fundamental do Centro de Educação Integral Francisco Frischmann², em Curitiba, na área de currículo e metodologia do ensino da Educação Física.

$\mathrm{Na}$ histórica consolidação das Redes Públicas de Ensino, muito se avançou no que se refere à Educação Pública de Qualidade, porém existem lacunas em algumas áreas do conhecimento em que a afirmação acima não representa uma verdade, observando-se equívocos e deturpações, como é o caso da Educação Física, tanto no que diz respeito à concepção de conhecimento, como também às questões de sistematização dos conteúdos e de encaminhamento metodológico, presentes, por exemplo, nos Currículos Básicos dessas Redes.

Este contexto acabou por proporcionar uma prática confusa e desvinculada do que pressupõe os fundamentos presentes nesses Currículos, o que caracteriza uma impossibilidade de tradução para a prática pedagógica dos avanços desta disciplina, que teoricamente já foram consolidados.

1 Este texto foi produzido a partir dos estudos desenvolvidos por um dos autores (Douglas D. Dittrich) no projeto "Fazendo Escola" (programa de incentivo à pesquisa da Rede Municipal de Ensino de Curitiba).

2 O Centro de Educação Integral Francisco Frischmann é uma escola que compõe a Rede Municipal de Ensino do Município de Curitiba, encontra-se localizada na periferia do mencionado município, e atende à comunidade através de duas formas de ensino, a chamada de tempo regular e a de tempo integral, em ambas as formas o que norteia a prática pedagógica da escola é o Currículo Básico da Rede Municipal. O projeto que aqui se relata foi desenvolvido nas terceiras e quartas séries do ensino regular, envolvendo duas turmas de terceira série e duas turmas de quarta série no período da tarde. 
Foi a partir deste entendimento que este estudo se colocou, visando compreender de forma mais pontuada os problemas acima, e propôs elementos que buscam dar conta de sustentar a prática pedagógica naqueles pontos citados.

Com vistas a que a disciplina de Educação Física possa contribuir com a desejada qualidade de ensino, objetivou-se com este projeto sistematizar os seguintes aspectos: a) Concepção de Conhecimento; b) Seleção e Sistematização dos Conteúdos; c) Encaminhamento Metodológico; d) Efetivação da Prática Pedagógica desta Disciplina.

\section{Cultura, currículo e conteúdo escolar}

Inicialmente é preciso entender que o conteúdo da disciplina Educação Física de $1 .{ }^{a} a$ 4. ${ }^{a}$ série do ensino fundamental advém da Cultura do Movimento Humano. Esta Cultura do Movimento Humano, ou qualquer outra nomenclatura que a literatura tenha produzido para definir esta parte do espectro do conhecimento humano ${ }^{3}$, é um compósito de saberes e valores afetos ao conhecimento do homem a partir de sua corporeidade, ou melhor dizendo, a partir da plenitude das suas expressões corporais.

Para entender melhor o que se denomina aqui de Cultura, utiliza-se das contribuições de SAVIANI (1989), para quem:

Cultura é, com efeito o processo pelo qual o homem transforma a natureza, bem como os resultados desta transformação. No processo de autoproduzir-se, o homem produz, simultaneamente em ação recíproca, a cultura. Isto significa que não existe cultura sem homem, da mesma forma que não existe homem sem cultura.

No universo escolar, a cultura é a matriz da qual emergem todos os saberes escolares. Isto é, no mundo social que é a escola, a cultura escolar é "o conjunto dos conteúdos cognitivos e simbólicos que, selecionados, organizados, 'normalizados', 'rotinizados', sob efeito dos imperativos de didati-

3 Elenor KUNZ (2000, p. 19) lembra que as terminologias variam um pouco, mas enfatiza que vários autores utilizando do termo "cultural corporal", podem estar reforçando - em verdade - um velho antagonismo entre corpo e mente, uma vez que se existe uma cultura corporal, é de se supor que exista uma cultura não-corporal ou intelectual. 
zação, constituem (...) o objeto de transmissão deliberada" (FORQUIN, 1993, p. 167)

No caso da área da Educação Física, a cultura do movimento humano sistematizada, ou nos termos de FORQUIN, "organizada, didatizada", produz o seu conteúdo. Isto é, essa "transposição didática"4 dos elementos dessa cultura, tematizados, produz o conteúdo da Educação Física Escolar.

Ou, como aqui se prefere afirmar, a sistematização desta cultura conduz aos Temas da Cultura do Movimento Humano, que aqui se entende como sendo o conteúdo da Educação Física Escolar. Isto é, tais temas devem passar por um crivo pedagógico, em que o relevante será a possibilidade de um tema em especial facilitar a compreensão da já mencionada Cultura do Movimento Humano.

Ademais, há que se atentar para a possibilidade deste tema de movimento contribuir para o que se compreende ser a construção do conhecimento:

Estando ligado organicamente à atividade laboriosa dos homens e à prática, o conhecimento (...) funciona a partir da prática e desenvolve-se da intuição viva ao pensamento abstrato, e do pensamento abstrato à prática, como critério de verdade. Repetindo um número infinito de vezes o ciclo: intuição viva - pensamento abstrato - prática, o conhecimento desenvolve-se, descobre novos aspectos e ligações e, em um certo estágio de seu desenvolvimento, começa a captar e a distinguir as propriedades e as ligações universais e a tomar consciência das leis universais da realidade e das formas universais do ser. (grifo nosso) (CHEPTULIN, 1982, p. 124)

Assim sendo, quando um tema de movimento possibilita verificá-lo a cada momento com aspectos e ligações novas, é porque ele tem relevância, é contemporâneo, apresenta simultaneidade para com os dados da realidade, dá condições de que o pensamento se efetive de forma espiralada e por estes motivos é provisório, portanto deve ser selecionado e então trabalhado com os alunos, buscando a cada momento fazer com que as crianças compreendam como a Cultura do Movimento Humano se concretiza, através da constante apreensão das propriedades e as ligações de um determinado Tema de Movimento. Este trabalho deve levar à percepção dos motivos pelos quais determinados Temas de Movimento encontram-se sistematizados em jogos com estruturas complexas, sendo esta a fase de Síntese do Conhecimento, onde o

4 VERRET (1975), citado por FORQUIN, Jean Claude. Escola e cultura. Porto Alegre: ArtMed., 1993. p. 16. 
aluno percebe as "ligações universais" do simples tema de movimento Lançar - por exemplo - dentro de toda a Cultura do Movimento Humano.

É assim que aqui se entende que a Educação Física escolar (para as séries iniciais do ensino fundamental) deva tratar a seleção e sistematização dos conteúdos, respaldada numa teoria consistente sobre o que vem a ser o conhecimento, e que apresente uma possibilidade de efetivação onde todos possam ver, com transparência, onde se quer chegar.

Para tanto, esta tarefa deve constar do Planejamento, devendo este apresentar uma proposta onde se possa perceber como é que se consolidará o que aqui ficou caracterizado como desenvolvimento do conhecimento e, com certeza, nesta perspectiva será necessária uma teoria que sustente e subsidie o processo educativo e que, portanto, também irá auxiliar no encaminhamento metodológico.

O referencial teórico não basta ser citado, ou seja, não se pode limitar a citar o Materialismo Histórico como matriz orientadora das análises deste trabalho. Faz-se necessário deixar claro o entendimento que se tem do mesmo.

Logo, quando aqui se faz a defesa de uma determinada perspectiva de apreensão do conhecimento, é porque está se balizando por um referencial que permite verificar quais as possibilidades de apropriação de conhecimento das crianças com quais a Educação Física Escolar lida. Ou ainda, cabe compreender quais os limites e possibilidades de apropriação do conhecimento por parte das crianças, que irão se confrontar com este saber.

A tradição na definição dos conteúdos e do tratamento metodológico na Educação Física dá a impressão de que as questões postas para a compreensão do conhecimento: "onde, quando e quem o produziu", são questões que devem abranger todos os "Ciclos de Desenvolvimento da Aprendizagem", não levando em consideração as diferenças entre os diversos alunos dos diversos "Ciclos de Desenvolvimento da Aprendizagem". Tratando as diferenças e as dificuldades a partir somente do referencial da psicomotricidade ou da divisão mais tradicional dos conteúdos da Educação Física (ginástica, jogo, dança, esporte), o que se propõe está longe de ter elementos coerentes para a efetivação pedagógica.

Da mesma forma, essas perspectivas mais costumeiras também não percebem se o aluno está ou não em condições de "captar e distinguir as propriedades e ligações universais" que o conhecimento possa apresentar, pois se entende que este seja o momento, como já dito anteriormente, da síntese do conhecimento, em que o aluno começará a perceber que determinados elementos da Cultura do Movimento Humano estão intimamente ligadas.

É por isso que, metodologicamente, a compreensão dos Temas de Movimento deve estar intimamente vinculada à possibilidade de: 
1. poder o Tema de Movimento fazer o caminho que a apreensão do conhecimento deve percorrer: "intuição viva - pensamento abstrato prática";

2. possibilitar a descoberta de "novos aspectos e ligações" presentes em si, mas que só com um olhar profundo pode ser evidenciado;

3. dar condições, para quem irá se apropriar dele, de "captar e distinguir as propriedades e as ligações universais";

4. por fim e em conseqüência da repetição constante e sucessiva dos três pontos anteriores, possibilitar através do esforço exercido no processo pedagógico, dar condições ao aluno de "tomar consciência das leis universais da realidade e das formas universais do ser".

Destarte, pensar a Educação Física no contexto escolar hoje, requer muita clareza na definição de qual concepção pedagógica se defende e a sua implementação no cotidiano escolar e, assim, como elemento preliminar a isso, ter ciência de que sociedade se objetiva construir e o que se pensa sobre os alunos quando se deparam com seu olhar incisivo, acreditando na máxima de que a Educação é sua única forma de ascensão social, ou de, pelo menos, poder participar de alguma forma da sociedade com a qual ele se depara todos os dias quando sai dos portões do maravilhoso e admirável mundo da escola.

Defende-se neste texto, uma sociedade democrática, participativa em todos os momentos para todas as pessoas: nos momentos da produção e da fruição do que foi produzido. Pensar nesta perspectiva, representa entender que o Capitalismo jamais conseguirá superar os limites que garantem sua própria sobrevivência, que é a apropriação privada do que coletivamente é produzido. Logo, isto requer a clareza de que o conhecimento com o qual a escola trabalha, não é uma propriedade privada do professor nem de ninguém, mas sim um produto que foi produzido por uma coletividade dentro das suas relações de produção, dentro dos limites impostos pelo modo de produção (o Capitalismo) e que, por serem propriedade de todos, precisam ser socializadas, e, ainda, que o mediador entre este processo de produção/socialização é o professor. Logo, se a estrutura da sociedade capitalista não permite socializar o que a humanidade produz na forma material, isso não ocorre (em partes) quando se menciona a produção "não material", , na qual ainda há condições de se executar tal socialização.

Entende-se portanto que cada disciplina que é trabalhada na Escola tem seu conteúdo a ser socializado e que cabe aos professores trabalharem este

5 KARL, Marx. Capítulo VI . Inédito de $O$ capital. São Paulo: Moraes. 
conteúdo da forma mais ampla possível $6^{6}$, buscando assim desvelar o mundo que se tem pela frente, compreendendo-o e participando efetivamente do mesmo.

Assim, para que este maravilhoso e admirável mundo não apenas não se perca dos olhos das crianças, mas como também para que este olhar mágico atue a favor delas mesmas, os educadores devem dizer a si mesmos o que querem quando adentram aos muros da Escola para dar aula, para que então possam dar mais força e esperança a este olhar mágico das crianças.

A despeito dos elementos até aqui apresentados, vale ainda ressaltar que, quando foi proposto apontar a superação da realidade, havia pelo menos dois motivos centrais para tanto: I. A não concordância com o paradigma de Educação Física hegemônico hoje nas escolas; II. Por se compreender que há outro projeto de sociedade que pode ser consolidado na Escola com vistas à libertação das classes populares.

Assim, este trabalho teve como linha mestra o entendimento de que o conhecimento historicamente produzido pela humanidade deve ser socializado ou, melhor dizendo: que as classes populares podem ter condições de se apropriar da verdade. Uma vez que a verdade vem lhes sendo negada, mesmo estando ela nos bancos de nossas Escolas Públicas através do que KOSIK (1977) chamou de "pseudoconcreticidade", que vem a ser a forma representativa pela qual determinado fenômeno se apresenta, dando condições apenas da apropriação da sua "aparência", condição pela qual os fenômenos são jogados à vista de todos de forma imediata, impossibilitando assim a apropriação dos fenômenos em sua essência, pois a coisa em si não se manifesta ao homem: Se os homens apreendessem imediatamente as conexões, para que serviria a ciência?, [e em $O$ capital, MARX vai afirmar que:] toda ciência seria supérflua se a forma fenomênica e a essência coincidissem diretamente. (MARX, In: KOSIK, 1977, p. 13)

Observe-se que se necessita agora de uma outra lógica de pensamento, não só na forma em que o conhecimento seja passado, na forma de ser absorvido, mas também é necessário um redimensionamento dos conteúdos

6 forma mais ampla possível: entende-se que é preciso ampliar os horizontes dos conteúdos que a escola trabalha em seus limites extremos, no entanto, esta ampliação não segue a lógica do senso comum, segundo a qual isto envolveria trabalhar conhecimentos de outras áreas, mas sim buscar expressar todas as inter-relações que fazem parte do conteúdo trabalhado, vinculando-o com uma visão de sociedade, processo este que em um determinado momento daria a condição de consolidar o que se denomina síntese do conhecimento, que seria o momento em que a junção de todas as disciplinas que são trabalhadas com a criança (cada qual com sua especificidade para traduzir o real), produziria a esta a condição de compreender e participar efetivamente da sociedade. 
transmitidos pela Educação Física dentro da escola. Para enriquecer a compreensão, SNYDERS (1974, p. 155-156) cita com muita propriedade Bachelard, que afirma:

\begin{abstract}
Entre o bom senso e o senso comum, observações naturais e a ciência, opera-se uma mudança total das perspectivas. 'O saber é' a negação das aparências, exige uma ruptura, uma conversão não só dos modos de pensamento, como ainda dos interesses e dos valores. Não se passa das impressões com que este termo implica de individual e de original (ou pelo menos com o que cada um julga ser original), ao conhecimento. Não se trata de algumas retificações, de um ajustamento lento e progressivo por aproximações sucessivas; mas dum primeiro ensaio intelectual.
\end{abstract}

Ou ainda, se necessita de uma forma diferenciada de se entender a construção da consciência do sujeito. Pois a consciência do sujeito é o reflexo da realidade e este reflexo adquire um caráter consciente vindo a manifestar-se sob a forma de conhecimento, o qual visa assegurar à sociedade as bases necessárias para a organização e desenvolvimento da produção, assim como a transformação do meio ambiente no interesse do homem.

O conhecimento apresenta graus de desenvolvimento e sua primeira forma é a tomada de consciência do homem de seu próprio existir, percepção do mundo que o cerca, passando a relacionar-se conscientemente com ele, vai construindo sua consciência, exercício este que é o próprio ato de apreender conhecimentos, através do movimento constante da "intuição viva - pensamento abstrato - prática" que se repete no homem um número infinito de vezes.

Nesta perspectiva, nos primeiros Ciclos de Desenvolvimento da Aprendizagem $^{7}$, devem ser trabalhados com as crianças 4 pontos, quais sejam:

1. Os movimentos básicos do homem (correr, saltar, pular, lançar, rolar etc.)

2. Quando a criança começa a compreender seu próprio existir, passa-se a fazer com que ela compreenda os significados de suas ações de movimento, o que a leva a perceber que há diferenças por, exemplo, entre correr de um cachorro e correr para pegar um amigo em uma brincadeira.

Este exercício é exatamente a passagem, por parte do aluno, da visão

7 Para Vygotsky (1991), o desenvolvimento da criança constitui-se em quatro ciclos, os quais não se encontram dissociados uns dos outros, não sendo também ilhas ou caixas fechadas em si mesmas, podendo a criança de um determinado ciclo, transitar em outro ciclo, dependendo do conteúdo a ser tratado e de suas relações sociais objetivas. 
difusa dos dados da realidade para uma fase superior, que é de organização e identificação de dados com vistas a formar sistemas, encontrar relações entre as coisas, identificando diferenças e semelhanças.

3. Entender as possibilidades de ela se relacionar com os objetos que a circundam (bolas diversas, perna de pau, bambolê, corda, bastão etc.)

A separação em si, com relação à natureza, supõe a tomada de consciência pelo homem da espacialidade, da existência dos objetos fora dele e, ao mesmo tempo, do aparecimento da representação, depois do conceito de espaço, das características espaciais. O conhecimento das particularidades das transformações intervindo na realidade ambiente, em decorrência da atividade laboriosa, conduz à formação do conceito de tempo, como medida de toda modificação e de todo movimento concretos. (CHEPTULIN, 1982, p. 125)

4. Participar construindo e reconstruindo jogos e brincadeiras simples, em que possam ser trabalhados o que os alunos já apreenderam, adquirindo, a partir daí, a compreensão do seu mundo de relações.

Pode-se observar a lei do movimento do conhecimento de uma categoria a outra no desenvolvimento dos conhecimentos científicos. Pelo fato de que as categorias são graus necessários do desenvolvimento do conhecimento social, o movimento de umas às outras deve necessariamente surgir em qualquer domínio do saber. (CHEPTULIN, 1982, p. 128)

Com base nas afirmações anteriores, para a Educação Física Escolar, os Temas de Movimento concretizam-se da forma que se segue:

1. ${ }^{\circ}$ É necessário saber sobre o tempo pedagógico de trabalho com os alunos: neste caso 200 dias divididos em dois períodos (semestres). Divide-se então o trabalho em dois momentos, aproveitando assim o que já se tem previsto em termos de organização tradicional do tempo na escola.

2. ${ }^{\circ}$ No primeiro semestre são trabalhados os Temas de Movimento: correr, lançar, rolamento, parada de mão, saltos (distância e altura), rebater, chutar.

3. ${ }^{\circ}$ Como exemplo do trabalho apresentado no primeiro semestre, na construção do conhecimento de que trata a Educação Física, serão abordados dois temas, sendo estes: lançar e o rebater. Observe-se: Ao trabalhar o lançar, percebe-se a necessidade de se compreender alguns pontos, os quais sejam: a- que o lançar é um Tema de 
Movimento; b- que se pode lançar diversos objetos; c- que uns objetos são mais prazerosos que outros para se lançar; d- que existem diversas formas de lançar, e sendo assim se percebe também que algumas são mais prazerosas que outras; e- experimenta-se diversos jogos que apresentam o tema lançar, mas dando aqui a importância maior na experienciação do lançar; f- diversos outros pontos relevantes que vieram a garantir que os alunos estabelecessem nexos, dependências e relações complexas possíveis sobre o tema lançar.

Com relação ao tema rebater, os pontos essenciais levantados são os seguintes: a- que o rebater é um Tema de Movimento; b- que o rebater pode se efetivar com e sem auxílio de objetos; c- com auxílio de objetos, verifica-se quais são os mais prazerosos para cada aluno e ou turma; d- quais os objetos mais prazerosos a serem rebatidos; e- as diferenças entre o lançar e o rebater; f- jogos onde se encontra o rebater; g- diversos outros pontos relevantes que garantam aos alunos estabelecer nexos, dependência e relações complexas possíveis sobre o tema rebater.

4. ${ }^{\circ}$ No segundo semestre são trabalhados os seguintes jogos: voleibol com bola gigante, bete ombro, caçador, futebol, e similares.

O trabalho com jogos no segundo semestre busca encontrar as relações entre os diversos temas e jogos, identificando as semelhanças e as diferenças, de forma que os alunos percebam porque os Temas de Movimento trabalhados no primeiro semestre acabam por estar presentes em jogos complexos, entendendo assim que alguns elementos é que são definidores para sua presença nestes jogos.

Esta análise e todo o processo, é o caminho da construção do conhecimento. Sendo este o entendimento, com o desenvolvimento desse projeto, nas Conclusões Possíveis, estão apontados os elementos que permitem entender a efetivação da prática pedagógica (o dia-a-dia) da Educação Física em uma nova perspectiva. 


\section{Conclusões possíveis}

\section{Sobre o papel da Educação Física nas séries iniciais do Ensino Fundamental}

Devido à democratização da possibilidade das crianças se movimentarem (mais particularmente se refere aqui às Escolas Públicas da periferia), muitas delas já chegam à Escola com domínio de alguns Temas de Movimento, pois é bem mais fácil ter onde correr ou ter uma pedra para lançar em um cachorro do que um bom livro para leitura ou mesmo um ambiente propício à leitura.

Poderia concluir-se que estes alunos não precisam da disciplina de Educação Física, o que é um equívoco, pois é justamente a partir do domínio destes Temas que se começa a construir relações na perspectiva de uma Cultura de Movimento Humano, em que através do lançar, consegue-se, em primeiro lugar, relacionar-se com os outros através dos Movimentos (jogos como o "Mãe Bola" propiciam isso) e, em segundo lugar, proporcionar uma compreensão do Tema que se esteja trabalhando, de forma que os alunos percebam que ele se efetiva de diversas formas e com diversos sentidos/significados, o que lhes impõe uma intenção a cada vez que o executam.

Portanto, no desenvolvimento deste trabalho, foi possível concluir que, ao falar da importância da disciplina de Educação Física nas quatro primeiras séries do Ensino Fundamental, deve-se trabalhar com a compreensão mais ampla possível de movimento humano, entendendo-o como Cultura e que é repleto de sentido (atribuído pelo indivíduo) e significado (atribuído pela sociedade) a cada vez que é executado.

Outro elemento importante a ser considerado é compreender como estes Temas acabam por consolidar e constituir os jogos mais complexos como caçador, bete ombro, futebol etc., e que, por serem representações da realidade social, são produtos Culturais.

Essa ampliação do Conhecimento Movimento Humano, é o passo indispensável para que os alunos possam fazer relações mais complexas da Realidade Social, sem esta ampliação o Movimento Humano passa a ser entendido como uma ação natural e, por consequiência, a realidade social pode também ser compreendida como natural e imutável. 


\section{A efetivação da Educação Física nas séries iniciais do Ensino Fundamental}

Com o desenrolar do projeto que deu origem ao texto, foi possível sistematizar algumas conclusões, as quais podem dar um norte na consolidação de uma proposta pedagógica para a educação física para as séries iniciais do Ensino Fundamental.

Tais conclusões fundam-se em quatro pontos, que consolidam o eixo da disciplina de Educação Física no Ensino Fundamental, sendo eles:

2.1 que os temas da cultura de movimento e os jogos são os principais conteúdos que a educação física deve tratar, obedecendo a seguinte ordem:

a) compreensão dos temas de movimento, b) ampliação da compreensão dos temas de movimento, c) aprender a jogar, d) compreender os jogos, e) aprender a construir os jogos.

2.2 que os encaminhamentos metodológicos para esta disciplina devem estar balizados por cinco momentos:

a) Apresentação verbal por parte do professor do conhecimento a ser trabalhado com os alunos, seus objetivos e sua dinâmica:

Neste primeiro momento é tarefa do professor em sala de aula apresentar o que será trabalhado com os alunos, que jogo será trabalhado, problematizando esta situação através de questionamentos que busquem fazer com que os alunos apresentem sua compreensão do conhecimento a ser tratado, assim como apresentem suas primeiras relações. Trata-se de uma retomada do que foi trabalhado no primeiro semestre, como, por exemplo, o lançar, que estará descontextualizado por força das circunstâncias.

O que é preciso considerar quando se vai analisar o tema lançar, é se ele possibilita compreender que o movimento humano se efetiva sempre com um significado, onde o mesmo tema lançar, pode possuir diversos significados, como: lançar para acertar, lançar para não acertar, lançar para um terceiro aluno sem que um segundo aluno tome posse, e até mesmo perceber que quando se lança uma pedra em uma vidraça há um significado que é diferente de quando se lança uma bola tentando evitar que quem joga junto tome posse dela, ainda que seja o mesmo tema de movimento, o que diferencia é o seu significado e esta compreensão dos significados é o ponto de partida para a seleção de conteúdos que devem ser trabalhados com as séries iniciais do ensino fundamental.

O professor deve perguntar: 
- Quais os Temas de Movimento presentes no jogo em questão?

- Que intenções permeiam os Temas de Movimento presentes neste jogo?

- Os sentidos/significados dos Temas de Movimento neste jogo são os mesmos de outros jogos já trabalhados?

No jogo de caçador, o lançar compõe-se de sentidos/significados que tornam este Tema de Movimento o mais prazeroso e importante do jogo, pois só é possível ganhar estando de posse da bola; já para o bete ombro sempre será preferível estar executando o Tema de Movimento rebater e não o lançar, pois aqui os sentidos/significados do lançar limitam-se à possibilidade de poder vir a rebater.

Sobre isto há uma passagem interessante, quando do trabalho com o jogo de caçador, ao retornar para a sala para conversar com os alunos sobre o que cada um percebeu dos Temas de Movimento no jogo: foi perguntado qual era o principal tema no caçador, ao que todos responderam ser o lançar. $\mathrm{Na}$ tentativa de ampliar a compreensão dos alunos, foi feito outro questionamento: - então o tema lançar será o tema principal e o mais prazeroso de ser vivenciado em todo jogo do qual fizer parte? Nova resposta. " - Sim professor".

Nesse momento, foi proposto que, na próxima aula, jogassem bete ombro e o professor esclareceu ser sua preferência vivenciar o tema rebater. Foi uma gritaria generalizada dizendo: “- Isso não vale professor, no bete todos nós preferimos rebater."

Assim foi aberta a possibilidade de ampliar a compreensão de um Tema de Movimento.

- É possível que um mesmo Tema de Movimento possa ter duas intenções diferentes no mesmo jogo, dependendo de qual papel se desempenha?

O correr no jogo de bete ombro apresenta duas intenções diferentes para quem está jogando, uma para quem corre para pegar uma bolinha rebatida e outra para quem corre por ter rebatido uma bolinha.

b) Representação gráfica da fala através de desenhos e/ou símbolos:

Entende-se neste trabalho, que é tarefa do professor fazer com que os alunos construam e consolidem sua possibilidade de apresentação tanto verbal como na forma escrita ou simbólica. Uma vez, que - conforme estudos de VIGOTSKY (1991) - o fato de um aluno deter as condições de compreensão e expressão de uma dada realidade (o jogo) através de uma forma de expressão (a verbal) não significa que este aluno apresente em si as condições de compreender e expressar esta mesma realidade (o jogo) através de outra forma de expressão (a escrita ou simbólica). 
Esta etapa ocorre junto com a fase anteriormente descrita.

É importante perceber aqui se os alunos conseguem efetivar as vivências que são apresentadas verbal/escrita e simbolicamente e em que medida isso passa a ocorrer com mais tranqüilidade, pois este será um elemento importante para caracterizar uma mudança qualitativa nos alunos.

c) Vivência prática do conhecimento trabalhado:

Após os dois momentos anteriores, este é o momento de realizar o que, a princípio, foi uma organização do que cada aluno trazia de sua experiência social, é aqui que as verdades são construídas, pois é justamente a prática o "critério de verdade" (CHEPTULIN, 1982, p. 124).

Nesse momento, é possível se fazer retomadas do que foi apresentado teoricamente.

d) retomada constante dos sentidos/significados possíveis para cada trabalho realizado e a construção de uma intencionalidade para cada trabalho:

Sendo a prática o critério de verdade, é indispensável que, ao estar jogando ou realizando Temas de Movimento, esteja o sujeito sempre confrontando os sentidos/significados presentes em nossos movimentos, assim como percebendo a possibilidade de construir novas intencionalidades para o Movimento Humano.

O trabalho com o Tema de Movimento saltar deve proporcionar, na prática, um confronto entre os sentidos/significados que permeiam este tema, no qual os alunos são colocados para saltar suas alturas transformadas em distância horizontal. A diferença entre saltar apenas uma distância e saltar uma distância que tem para cada um deles um valor, proporciona aos alunos perceberem e reconstruírem suas intenções a cada vez que executam tal movimento. $\mathrm{O}$ mesmo ocorre quando se deparam com a tentativa de superar a altura do menor aluno da turma, agora na vertical, o aluno passa a se transformar em gigante e o movimento saltar toma outras proporções.

No correr, é interessante perceber e vivenciar como este movimento se apresenta quando é realizado em diferentes circunstâncias, como ao correr de um cachorro, correr para pegar alguém, correr para fugir de alguém, correr para chegar rápido, correr para chegar, sem se preocupar em ser rápido ou demorado, correr para salvar alguém, e diversas outras situações em que será encontrado o Tema de Movimento correr com diferentes sentidos/significados, que impõem uma intenção diferente a cada momento, em que percebe-se que, ao executá-lo, pode-se sentir medo, alegria, prazer, raiva, tristeza, sensação de superação etc. 
O chutar, dentro do futebol, apresenta uma variação enorme de intenções, uma criança que chuta a bola para fora de campo buscando evitar um gol tem em sua ação de movimento duas intenções bem perceptíveis, são elas: evitar o gol e chutar para ninguém pegar a bola.

Já quando ela está com a bola em seu domínio e passa para um colega, tem a intenção de fazer, através de sua ação de movimento, com que a bola chegue a seu colega, que se encontra em movimento ou parado.

Outra circunstância seria quando ela chuta para fazer o gol, ela busca acertar um alvo, diferente da primeira situação mencionada, e tem que evitar que o goleiro pegue a bola, diferente também da segunda situação.

O que dizer então do chutar a bola de calcanhar? Como uma ação isolada, fora do contexto do jogo de futebol, é uma ação de movimento completamente desprazerosa, mas quando realizada dentro de um jogo, é um movimento de alto prazer e demonstra como quem o realizou sabe jogar. É importante perceber aqui que o movimento chutar com o calcanhar só é realizado justamente por uma beleza e prazer em sua ação. Um jogador que usa esta jogada não procura o eficiente, mas sim o belo.

e) reconstrução do jogo a partir do trabalho de sua compreensão e de seu sentido/significados, balizados agora por uma nova intenção:

Há ainda uma tarefa que vise concluir os trabalhos sobre um Tema de Movimento ou um Jogo, na qual o professor deverá dedicar uma semana ou uma aula, dependendo das circunstâncias, para que os grupos de alunos possam construir novos sentidos/significados e intenções para os Temas de Movimento e para os Jogos.

Esses cinco pontos acima dão condições de fazer com que os alunos não joguem mecanicamente ou saibam a história dos jogos mecanicamente, mas sim que compreendam as diversas possibilidades de intenções que permeiam os jogos através de seus sentidos/significados, como também possibilitará aos alunos poder ver o movimento humano como uma obra culturalmente construída, que, dependendo das relações que se efetivam, terá intencionalidades diferentes. E, é claro, também terá construído um instrumental que lhe permite ter prazer ao jogar.

\subsection{Seleção e sistematização dos conteúdos}

No decorrer do trabalho, buscou-se consolidar a compreensão que $o$ conteúdo de que trata a disciplina Educação Física nas quatro primeiras séries do Ensino Fundamental são os Temas de Movimento e os Jogos. 
Desta forma, cabe dar conta de como deveriam ser organizados, sistematizados e distribuídos os conteúdos, assim como o tempo pedagogicamente necessário à sua assimilação, para o que é defendida a proposta que se segue.

a) sistematização dos conteúdos:

Divisão do ano letivo em dois períodos, primeiro e segundo semestre, tomando de empréstimo como marco referencial de um salto de qualidade dos alunos, as férias pedagógicas do meio do ano.

Assim, no primeiro semestre, trabalham-se os Temas de Movimento e como eles vem a efetivar a Cultura de Movimento, trabalhando com vistas ao desvelamento de seus sentidos/significados, para que os alunos consolidem uma consciência sobre os Temas de Movimento, nos quais todos os temas relevantes são trabalhados com vistas a que os alunos, ao executarem um tema, saibam os valores que permeiam este movimento, sabendo diferenciar os valores que os outros impuseram no referido movimento daqueles impostos individualmente.

Já para o segundo semestre, devem ser selecionados Jogos que permitam um aprofundamento da compreensão dos Temas de Movimento e que também sejam culturalmente relevantes.

b) critérios de seleção dos conteúdo:

Aqui são usadas como subsídio as contribuições do "Coletivo de Autores", , para quem os critérios devem ser os que se seguem: Relevância social do conteúdo; Contemporaneidade do conteúdo; Adequação às possibilidades sociocognoscitivas do aluno; Simultaneidade dos conteúdos enquanto dados da realidade; Espiralidade da incorporação das referências do pensamento; Provisoriedade do conhecimento.

\subsection{O conhecimento de que trata a Educação Física}

Com os estudos e com o desenvolver deste projeto, entende-se que o conteúdo da disciplina Educação Física de $1 .{ }^{a} a 4{ }^{a}{ }^{a}$ série do ensino fundamental são os Temas da cultura de movimento humano. Tais temas, após sistematizados, devem passar por um crivo pedagógico, em que o relevante será a possibilidade de um tema em especial contribuir para com a compreensão da já mencionada Cultura do Movimento Humano, e esta deve garantir a ampliação da compreensão da realidade por parte de quem a acessa.

8 COLETIVO DE AUTORES. Metodologia do ensino da Educação Física. São Paulo: Cortez, 1992. 
Essa dimensão cultural do movimento do homem, ocorre com todos os movimentos entendidos como básicos do homem, por serem uma construção.

Isto se deve ao fato de os mesmos serem construídos em sociedade (nas relações sociais), esta ação humana tem um aspecto cultural indissociável em seu existir, mesmo que tão pouco trabalhado e percebido, até mesmo na Educação Física.

Aqui concordamos com KUNZ (1991), que também defende ser o movimento humano o conteúdo principal da Educação Física:

\begin{abstract}
Na prática da Educação Física nas Escolas a padronização do movimento no sentido da concepção do esporte de rendimento se estabilizou a tal ponto que a realização destes movimentos esportivos é recebida e aceita como 'uma solução quase que natural de toda a problemática do Movimento Humano'. Só que, com isto, um horizonte de movimentos significativos para a vida das crianças pode ser eliminado pela Educação Física. É por este motivo que tento privilegiar o Movimento Humano no ensino da Educação Física e não os esportes normatizados. Mas o movimento, como tema central de aula, também não pode ter um enfoque biomecanicista ou Behaviorista, mas sim, deve ser visto e interpretado como expressão humana, como função dialógica na relação Homem/Mundo. O tema central de uma aula de Educação Física, assim concebida, é permeado por múltiplas perspectivas para o desenvolvimento e a interpretação do movimento, onde o movimento dos esportes normatizados compõe apenas uma parte deste Mundo do Movimento. (KUNZ, 1991, p. 185)
\end{abstract}

Assim, o conhecimento estará ampliando seus elos, suas ligações, seus nexos, contribuindo para que aquele que o acessa tenha melhores condições de entender e participar do mundo ao qual pertence.

\title{
REFERÊNCIAS
}

CASTELLANI FILHO, Lino. Educação Física no Brasil: a história que não se conta. Campinas: Papirus, 1988.

CHEPTULIN, Alexandre. A dialética materialista. São Paulo: Alfa-Omega, 1982.

COLETIVO DE AUTORES. Metodologia do ensino de Educação Física. São Paulo: Cortez, 1992.

FORQUIN, Jean Claude. Escola e cultura. Porto Alegre: ArtMed., 1993.

KOSIK, Karel. O mundo da pseudoconcreticidade e sua destruição. In: Dialética do concreto. Rio de Janeiro: Paz e Terra, 1977. 
DITTRICH, D. D. Educação Física escolar: cultura...

KUNZ, Elenor. Educação Física: ensino e mudanças. Ijuí: Unijuí, 1991.

MARX, Karl. O capital: capítulo VI. São Paulo: Moraes.

SAVIANI, Dermeval. Do senso comum à consciência filosófica. São Paulo: Cortez, 1989.

VYGOTSKY, Lev S. A formação social da mente. São Paulo: Martins Fontes, 1991. 